\title{
Bafa Gölü Sularında Element Konsantrasyonlarının Belirlenmesi ve Su Kalitesi Açısından Değerlendirilmesi
}

\author{
Melik KARA* \\ Dokuz Eylül üniversitesi, Çevre Mühendisliği Bölümü, Tınaztepe Kampüsü, Buca, İzmir
}

\begin{abstract}
Öz
Türkiye'nin güneybatısında yer alan büyük göllerimizden biri konumundaki Bafa Gölünden Nisan 2018 döneminde 10 noktadan yüzeysel su örnekleri toplanmıştır. Toplanan örneklerde ICP-MS (Endüktif Eşleşmiş Plazma - Kütle Spektrometresi) cihazı kullanılarak ağır metal ve eser element ölçümleri yapılmıştır. Ölçüm sonucunda elde edilen değerler farklı kategorilerdeki su kalitesi sınıflama ve sınır değerleri ile karşılaştırılarak göl suyu kalitesi incelenmiştir. Doğal kaynaklı elementlerden $\mathrm{Na}, \mathrm{Mg}, \mathrm{K}$ ve $\mathrm{Ca}$ değerleri sırasıyla en yüksek konsantrasyonlarda ölçülürken, toksik ya da tehlikeli olabilen ağır metallerden As ve Zn sırasıyla 15,3 ve 51,2 $\mu \mathrm{g} / \mathrm{L}$ olarak ölçülmüştür. Element konsantrasyonlarının istatistiksel dağılım parametrelerinden çarpıklık ve basıklık, Sn, P, Ni, Pb, As, Cd, Tl, Co, Mo ve Cu elementlerinin antropojenik kaynaklı olabileceğini göstermiştir. Su Kirliliği Kontrolü Yönetmeliği ve Yerüstü Su Kalitesi Yönetmeliği kapsamında verilen sınıflama ölçütleri dikkate alındığında göl suyunun Na ve P parametreler dışında 1. Sınıf sular kapsamına dâhil olduğu görülmektedir. Ayrıca hayvansal ve tarımsal amaçlı kullanılan suların taşıması gereken kalite ölçütleri ile de karşılaştırılan değerler uygun bulunmuştur.
\end{abstract}

Anahtar kelimeler: Bafa Gölü, Ağır Metaller ve Eser Elementler, Su Kalitesi, Yasal Düzenlemeler.

\section{The Determination of Elements Concentrations in the Bafa Lake and the Evaluation of Water Quality}

\begin{abstract}
Surface water samples were collected from 10 sites in April 2018 from Bafa Lake, which is one of our large lakes in southwest Turkey. Samples were analyzed for heavy metals and trace elements using ICP-MS (Inductively Coupled Plasma-Mass Spectrometry). Lake water quality was examined by comparing the water quality classification and limit values in different regulations. While the natural origin elements $\mathrm{Na}, \mathrm{Mg}, \mathrm{K}$ and $\mathrm{Ca}$ were measured at the highest concentrations, As and Zn which may be toxic or hazardous were measured as 15,3 and $51,2 \mu \mathrm{g} / \mathrm{L}$, respectively. When the skewness and kurtosis parameters of the element concentrations were investigated, it was found that the elements of $\mathrm{Sn}, \mathrm{P}, \mathrm{Ni}, \mathrm{Pb}, \mathrm{As}, \mathrm{Cd}, \mathrm{Tl}, \mathrm{Co}$, Mo and $\mathrm{Cu}$ were likely to reach from anthropogenic sources to the lake. Considering the classification criteria under Water Pollution Control Regulation and Surface Water Quality Regulation, the lake water is included in the $1^{\text {st }}$ class waters except $\mathrm{Na}$ and $\mathrm{P}$ parameters. In addition, the water quality was also found to be appropriate in terms of quality criteria for water used for livestock and agricultural purposes.
\end{abstract}

Keywords: Bafa Lake, Heavy Metals and Trace Elements, Water Quality, Legal Regulations.

\section{Giriş}

Sucul ortamlarda ağır metaller ve eser elementler çevresel ortamlardaki kalıcılıkları, biyojeokimyasal geri dönüşümleri ve ekolojik etkileri nedeniyle ölçülmesi ve izlenmesi gereken parametrelerdir. Yüzeysel sularda ve sediment tabakasındaki $\mathrm{As}, \mathrm{Cd}, \mathrm{Cr}, \mathrm{Hg}, \mathrm{Se}, \mathrm{Pb}$, Ni gibi bazı elementler çok düşük konsantrasyonlarda bile toksik etkilere sahip olabilmekte ve ekosistem için potansiyel bir tehdit oluşturabilmektedir [1,2]. Ayrıca, bu elementler kolayca besin zincirine katılarak doğada bulunan

*Sorumlu yazar: melik.kara@deu.edu.tr

Geliş Tarihi: 12.10.2018, Kabul Tarihi: 05.01.2019 
canlıların bünyelerinde birikmeleri nedeniyle diğer kimyasal kirleticiler içerisinde ilk sıralarda yer almaktadır [3].

Ağır metaller ve eser elementler, doğal süreçler ve antropojenik aktiviteler ile sucul ekosistemlere ulaşarak hem su hem de sediment tabakasında bulunabilmektedirler. Yüzeysel akış, arıtılmadan sucul ortama verilen atık sular ve atmosferik çökelme, elementel kirliliğin başlıca antropojenik kaynaklarıdır [4-6]. Doğal kaynakları ise su tabanındaki ve çevresindeki kabuksal kayalarla suyun fiziksel ve kimyasal etkileşmesinden kaynaklanan girdiler oluşturmaktadır [7-10]. Su ortamında çözünmüş elementlerin çökelmiş parçacıklara sorpsiyonu veya organizmaların bünyesine girmesi ile biyolojik fazlara katılarak sediment tabakasına aktarılması söz konusudur. Sediment tabakasında biriken bu elementler farklı kimyasal mekanizmalar ile yeniden su sütununa karışarak su içindeki içsel geri dönüşümünü tekrar etmektedir [10,11].

Su kalitesi, belirli bir su örneğinde bulunan ve kimyasal bileșimini oluşturan maddelerin miktarını ve etkilerini ifade etmektedir. Nehirler ve göller gibi sucul ortamlar doğrudan ya da dolaylı olarak insan refahına ve sucul canlı yaşamına katkıda bulunmaktadır [12]. Ülkemizde yerüstü suları ile kıyı ve geçiş sularının biyolojik, kimyasal, fiziko-kimyasal ve hidromorfolojik kalitelerinin belirlenmesi, sınıflandırılması, su kalitesinin ve miktarının izlenmesi, bu suların kullanım maksatlarının sürdürülebilir kalkınma hedefleriyle uyumlu bir şekilde korunması için alınacak tedbirler ve uygulamalar yönetmelikler ile belirlenmektedir [13]. Bununla beraber ülkemizdeki mevcut yüzeysel su kaynaklarının ekolojik ve kimyasal durumlarıyla ilgili yeterli veri halen birçok bölge için eksik kalmaktadır. Su kaynaklarının sürdürülebilir bir şekilde yönetilmesi için su kalitesinin çok iyi belirlenip takip edilmesi gerekmektedir.

Ege Bölgesinde yer alan Bafa Gölü ekolojik özellikleri, kuş türleri ve kültürel yapısıyla önemli bir doğal kaynak gölüdür. Son yıllarda bölgedeki hızlı nüfus artışına bağlı olarak Büyük Menderes Nehri'nde meydana gelen kalite ve miktar değişimlerinden olumsuz yönde etkilenmektedir. Gölün zaman içerisinde büyük ölçüde değişmiş olmasının yanı sıra su kalitesi de zayıf olarak sınıflandırılmaktadır [14]. Bafa Gölü için önemli kirlilik kaynakları olarak bazı unsurlar ortaya çıkmaktadır. Gölü besleyen ve yüksek miktarda kirletici madde içeren Büyük Menderes Nehri bunların başında yer almaktadır [15]. Diğer bir unsur, göl çevresinde kurulan ve kanalizasyon alt yapıları olmayan yerleşimlerden (Kapıkırı, Gölyaka, Serçin vb.) gelen evsel atık sulardır. Göl civarındaki düzlüklerde gerçekleştirilen tarımsal ve hayvancılık faaliyetlerinin ve göl kıyısında bulunan balık yetiştirme çiftliklerinin de göl suyu kalitesi üzerinde olumsuz etkisi bulunmaktadır. Su kalitesini etkileyen diğer bir kaynak ise, özellikle alanın güneydoğusunda yoğunluk kazanmış olan zeytin işleme tesislerinden gelen atık sulardır. Gölün çevresinden geçen, yaz aylarında daha da yoğun olan karayolu araç trafiğine ek olarak yol üzerinde bulunan küçük tesis ve işletmeler de gölün kirlenmesine sebep olmaktadir [16].

Bafa Gölü'nde Yılgör [8] tarafından gerçekleştirilen ve göl sedimentlerindeki element konsantrasyonlarının belirlendiği çalışmada, gölde yapılacak ileriki araştırmalarda elementel kirliliğin insan sağlığ 1 ve canlı yaşam üzerindeki etkilerinin belirlenebilmesi için, element konsantrasyonlarının göl suyunda ve gölde yaşayan canlı türlerinde belirlenmesi önerilmektedir. Ayrıca Yabanlı vd. [17] göl suyu örneklerinde ve gölden elde edilen levrek balığı dokularında ağır metal ( $\mathrm{Al}, \mathrm{Cr}, \mathrm{Ni}, \mathrm{Cu}, \mathrm{As}, \mathrm{Cd}$, $\mathrm{Hg}, \mathrm{Pb}$ ) varlı̆̆ını mevsimsel olarak incelemiştir. Bu yakın dönemde gerçekleştirilen iki çalışmanın ardından göl suyu kalitesinin belirlenmesine yönelik herhangi bir çalışma gerçekleştirilmemiştir.

$\mathrm{Bu}$ çalışmada Bafa Gölü'nden toplanan su örneklerinde ağır metal ve eser element konsantrasyonları belirlenmiştir. Ölçüm sonucunda elde edilen değerler farklı kategorilerdeki su kalitesi sınır değerleri ile karşılaştırılarak göl suyu kalitesi incelenmiştir. Ayrıca istatistiksel yöntemler kullanılarak kirliliğe sebep olan kaynaklar belirlenmeye çalışılmıştır.

\section{Materyal ve Metot}

\section{1. Çalıșma Alanı}

Bafa Gölü, Türkiye'nin güneybatısında Büyük Menderes Deltası'nın güneydoğusunda Muğla ile Aydın il sınırı arasında yer alan bir göldür (Şekil 1). Büyük Menderes Nehri’nin körfez ağzına yığdığ alüvyonlardan dolayı delta ilerlemesi sonucunda denizle bağlantısı kesilerek oluştuğu bilinmektedir. Bafa Gölü $37^{\circ} 31^{\prime}$ Kuzey ve $27^{\circ} 27^{\prime}$ Doğu koordinatlarında yer almaktadır. Genel olarak Büyük 
Menderes Nehri ile beslenmekte olup yağışın bol olduğu zamanlarda Beşparmak Dağları'ndan dökülen küçük dereler de göle ulaşmaktadır. Gölden çıkış ise Bafa Çayının yine Büyük Menderes nehrine bağlantısı ile olmaktadır. Gölün kuzeybatı kısmı sığlık olmakla beraber maksimum derinlik ortalama 20 m ve yüzey alanı yaklaşık $75 \mathrm{~km}^{2}$ 'dir. Gölün su seviyesi özellikle yaz aylarında Büyük Menderes Nehri'nden tarım sulaması maksadıyla su çekildiği için düşmektedir [8].

Gölün yakın çevresinde balık yetiştirme çiftlikleri, zeytinyağı üretim fabrikaları, restoranlar, moteller ve kamp alanları faaliyet göstermektedir. Bununla beraber yerleşim birimleri ve tarım arazileri de yer almaktadır. Tüm bu faaliyet ve alanlardan oluşan sular göle deşarj edilmektedir. Ayrıca, gölün güney ve batı kıyısı boyunca yaz aylarında oldukça yoğun olan Milas-Söke (D525) karayolu geçmektedir.

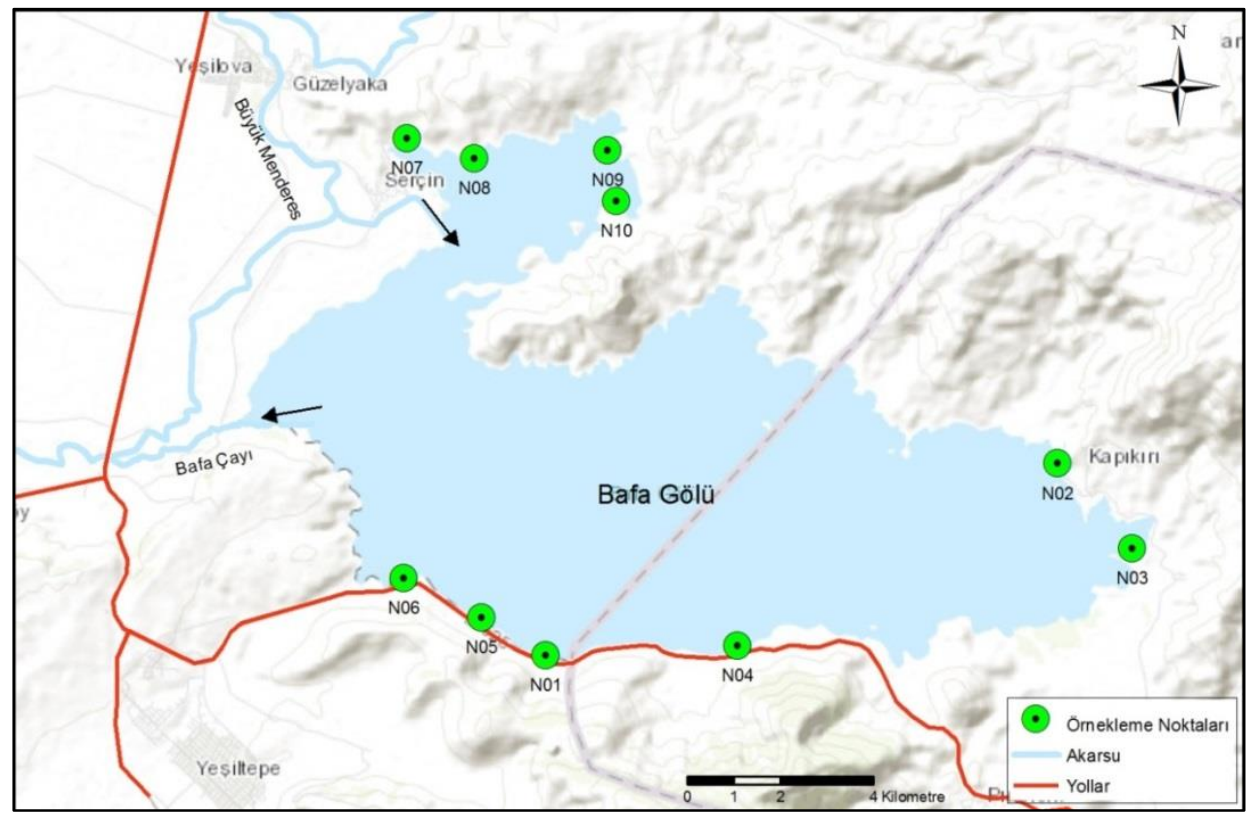

Şekil 1. Bafa Gölü ve örnekleme noktalarının yerleşimi

\subsection{Deneysel Metodoloji}

Çalışmanın amacına uygun olarak su kalitesinin belirlenmesine yönelik gölün kıyı bölgelerinden olmak üzere 26 Nisan 2018 tarihinde Şekil 1 de gösterilen 10 noktadan su örneği toplanmıştır. Alınan örneklerde fiziksel parametreler $(\mathrm{pH}$, elektriksel iletkenlik) ile ağır metal ve eser element konsantrasyonları belirlenmiştir. Fiziksel parametreler ( $\mathrm{pH}$ ve elektriksel iletkenlik) WTW Inolab pH720/Cond720 cihazı kullanılarak ölçülmüştür.

Element analizleri için örnekler, 2-3 kez göl suyu ile yıkanmış $250 \mathrm{ml}$ polietilen kaplara alınmıştır. Laboratuvara getirilmeden önce $\mathrm{pH}<2$ olacak şekilde $\mathrm{HNO}_{3}$ ile asitlendirilen örnekler, laboratuvarda 0,45 $\mu \mathrm{m}$ PTFE filtreden geçirilerek analize hazırlanmıştır. 61 elementin (Ag, Al, As, B, $\mathrm{Ba}, \mathrm{Be}, \mathrm{Bi}, \mathrm{Ca}, \mathrm{Cd}, \mathrm{Ce}, \mathrm{Co}, \mathrm{Cr}, \mathrm{Cs}, \mathrm{Cu}, \mathrm{Dy}, \mathrm{Er}, \mathrm{Eu}, \mathrm{Fe}, \mathrm{Ga}, \mathrm{Gd}, \mathrm{Ge}, \mathrm{Hf}, \mathrm{Hg}, \mathrm{Ho}, \mathrm{In}, \mathrm{K}, \mathrm{La}, \mathrm{Li}, \mathrm{Lu}, \mathrm{Mg}$, Mn, Mo, Na, Nb, Nd, Ni, P, Pb, Pr, Rb, Sb, Sc, Se, Si, Sm, Sn, Sr, Ta, Tb, Te, Th, Ti, Tl, Tm, U, V, W, Y, Yb, Zn, Zr) analizi ICP-MS (Endüktif Eşleşmiş Plazma - Kütle Spektrometresi) (Agilent 7700x HMI) cihazı ile gerçekleştirilmiştir.

\section{3. İstatiksel Değerlendirme}

$\mathrm{Su}$ örneklerinin elementel konsantrasyonlarının istatistiksel analiz ve değerlendirmelerinde IBM SPSS V24 programı kullanılmıştır. Her bir parametre için ortalama, medyan, standart sapma, minimum ve maksimum değerlerinin yanı sıra dağılım ölçütlerinden Çarpıklık (Skewness) ve Basıklık (Kurtosis) parametreleri de hesaplanmıştır.

Çarpıklık arttıkça mod ve ortalama birbirinden uzaklaşır. Eğer ortalama medyandan küçük ise dağılım sola (negatif), eğer ortalama medyandan büyük ise dağılım sağa (pozitif) çarpık olur. Çarpıklık 
ölçüsü \pm 2 aralığında değerler alması durumunda normal kabul edilmektedir. Doğada, eğer bir eleman antropojenik kaynaklardan etkilenmezse, normal bir dağılımı izlemektedir. Basıklık (Kurtosis) normal dağılım eğrisinin ne kadar dik veya basık olduğunu gösterir. Yüksek basıklık değerine sahip veri setlerinde eğri normale göre daha diktir ve aykırı değerlere sahip olma eğilimindedir. Düşük basıklık değerine sahip veri setlerinde ise normal dağılıma göre daha basıktır ve veri seti aykırı değerlere sahip değildir.

\section{Bulgular ve Tartışma}

Bafa Gölü yüzey suyunda 10 noktadan toplanan örneklerde ağır metal ve eser element konsantrasyonları

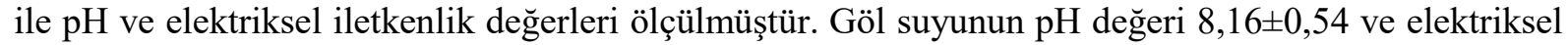
iletkenlik değeri $19732 \pm 1311 \mu \mathrm{s} / \mathrm{cm}$ olarak ölçülmüsstür. En düşük elektriksel iletkenlik değerleri gölün kuzeybatı kısmında yer alan sığlık alanda ölçülürken bu alanın dışında kalan diğer örnekleme noktalarında ölçülen değerler $\sim 21000 \mu \mathrm{s} / \mathrm{cm}$ seviyelerinde tespit edilmiştir.

Ölçümü yapılan ağır metal ve eser element konsantrasyonları ile istatistiksel hesaplamalar Tablo 1'de verilmektedir. Doğal kaynaklı elementlerden $\mathrm{Na}, \mathrm{Mg}, \mathrm{K}$ ve $\mathrm{Ca}$ sirasiyla en yüksek konsantrasyonlarda ölçülmüştür. Bu elementleri yine doğal olarak sularda yüksek konsantrasyonlarda bulunan $\mathrm{Sr}, \mathrm{Si}, \mathrm{B}, \mathrm{Al}, \mathrm{P}, \mathrm{Li}$ ve Ba izlemektedir. Antropojenik kaynaklardan suya karışması olası olan $\mathrm{Mo}, \mathrm{Cu}$, Ni ve V konsantrasyonları sirasiyla 2,33-12,01 $\mu \mathrm{g} / \mathrm{L} ; 0,24-8,37 \mu \mathrm{g} / \mathrm{L} ; 1,63-3,42 \mu \mathrm{g} / \mathrm{L}$ ve $0,93-$ $1,97 \mu \mathrm{g} / \mathrm{L}$ aralığında ölçülmüştür. Gölde ölçülen en düşük değerler ise nadir toprak elementlerine (Ce, Dy, Er, Eu, Gd, Ho, La, Lu, Nd, Pr, Pm, Sm, Sc, Tb, Tm, Yb, ve Y) aittir.

Düşük konsantrasyonlarda bile toksik ya da tehlikeli olabilen ağır metal değerleri As, $\mathrm{Cd}, \mathrm{Cr}$, $\mathrm{Cu}, \mathrm{Hg}, \mathrm{Pb}, \mathrm{Se}, \mathrm{Tl}$ ve $\mathrm{Zn}$ için sırasıyla en yüksek 15,3 $\mu \mathrm{g} / \mathrm{L} ; 0,05 \mu \mathrm{g} / \mathrm{L} ; 0,22 \mu \mathrm{g} / \mathrm{L} ; 8,37 \mu \mathrm{g} / \mathrm{L} ; 0,06 \mu \mathrm{g} / \mathrm{L}$; $0,33 \mu \mathrm{g} / \mathrm{L} ; 0,45 \mu \mathrm{g} / \mathrm{L} ; 0,04 \mu \mathrm{g} / \mathrm{L}$ ve $51,2 \mu \mathrm{g} / \mathrm{L}$ olarak belirlenmiştir.

Element konsantrasyonlarının istatistiksel olarak dağılımları çarpıklık ve basıklık parametreleri için Tablo 1'de gösterilmektedir. $\mathrm{Bu}$ parametreler incelendiğinde antropojenik kaynaklardan etkilenmesi olası elementler için yüksek, doğal oluşumlardan etkilenen elementler için düşük çarpıklık ve basıklık değerleri hesaplanmıştır. $\mathrm{Sn}, \mathrm{P}, \mathrm{Ni}, \mathrm{Pb}, \mathrm{As}, \mathrm{Cd}, \mathrm{Tl}, \mathrm{Co}$, Mo ve $\mathrm{Cu}$ elementleri için hesaplanan asimetrik ve dik dağılım değerleri bu elementlerin göle ağırlıklı olarak antropojenik kaynaklardan girdiğini göstermektedir. Diğer taraftan ekseriyetle doğal oluşumlarda yer alan $\mathrm{Sr}, \mathrm{Na}, \mathrm{Mg}, \mathrm{Ca}, \mathrm{K}, \mathrm{Si}$ ve Li için bu dağılım değerleri normal dağılım göstermiş̧ir.

Gölde örnekleme yapılan 10 nokta arasından elementler için en yüksek değerler N01 noktasında (36 element için) ve N07 noktasında (8 element için) ölçülmüştür. Şekil 2'de gölde ölçülen ve gölün karakteristiği ile ilgili bilgiler veren $\mathrm{Na}$ ve $\mathrm{P}$ için yersel dağılımlar verilmektedir. Ayrıca toksik etkiler gösteren elementlerin (As, Cd, Cr, Cu, Mo, Ni, Se ve Pb) konsantrasyonları için yersel dağılımlar Şekil 3 'te verilmektedir.
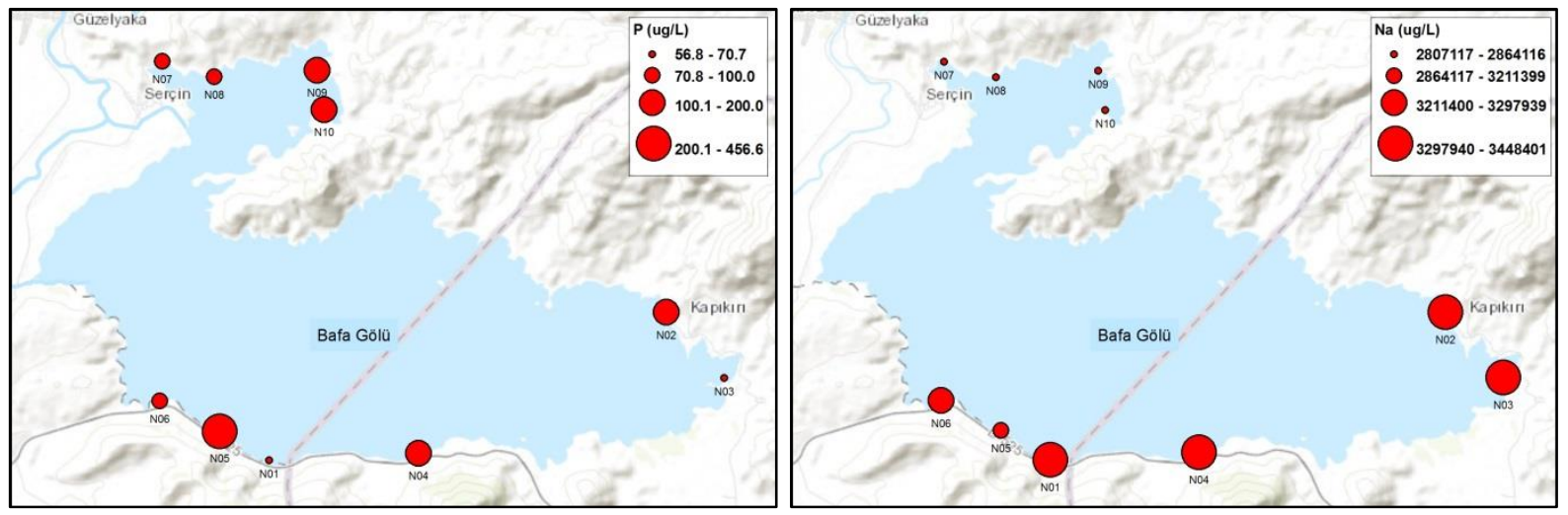

Şekil 2. P ve Na konsantrasyonlarının yersel dağı̆ımları 

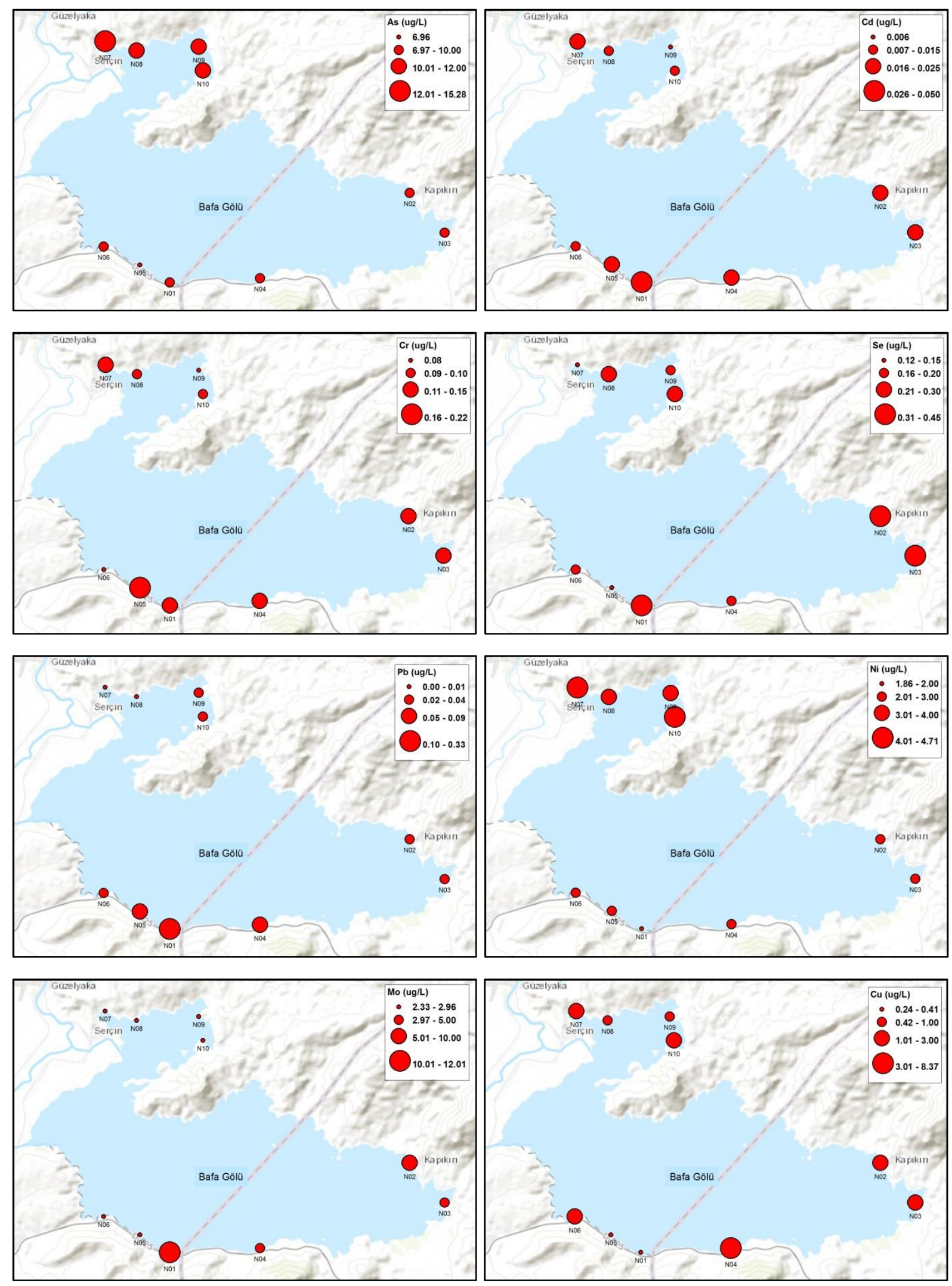

Şekil 3. $\mathrm{As}, \mathrm{Cd}, \mathrm{Cr}, \mathrm{Cu}, \mathrm{Mo}, \mathrm{Ni}$, Se ve $\mathrm{Pb}$ konsantrasyonlarının yersel dağılımları 
Tablo 1. Gölde ölçülen ağır metal ve eser element konsantrasyonları ( $\left.\mu \mathrm{g} / \mathrm{L},{ }^{*} \mathrm{mg} / \mathrm{L}\right)$ ve istatistiksel değerler

\begin{tabular}{|c|c|c|c|c|c|c|c|c|c|}
\hline Elem. & Ort. & Min - Mak & $\begin{array}{l}\text { Çarpıklık } \\
\text { (skewness) }\end{array}$ & $\begin{array}{c}\text { Basıklık } \\
\text { (Kurtosis) }\end{array}$ & Elem. & Ort. & Min - Mak & $\begin{array}{c}\text { Çarpıklık } \\
\text { (skewness) }\end{array}$ & $\begin{array}{c}\text { Basıklık } \\
\text { (Kurtosis) }\end{array}$ \\
\hline $\mathrm{Na}^{*}$ & 3153 & $2807-3448$ & $-0,30$ & $-2,15$ & $\mathrm{Cr}$ & 0,118 & $0,08-0,22$ & 1,65 & 3,70 \\
\hline Mg* & 386 & $348,1-429,2$ & $-0,02$ & $-1,95$ & Ge & 0,117 & $0,02-0,27$ & 0,59 & $-1,36$ \\
\hline $\mathbf{K}^{*}$ & 118 & $92,7-151,3$ & 0,30 & $-1,56$ & $\mathbf{B e}$ & 0,074 & $0,05-0,13$ & 1,25 & 0,70 \\
\hline $\mathrm{Ca}^{*}$ & 58,7 & $55,2-63,1$ & 0,08 & $-1,08$ & $\mathbf{P b}$ & 0,067 & $0-0,33$ & 2,71 & 7,83 \\
\hline $\mathrm{Sr}$ & 3800 & $3445-4049$ & $-0,83$ & 1,38 & $\mathbf{N b}$ & 0,053 & $0,02-0,16$ & 1,95 & 3,78 \\
\hline $\mathbf{S i}$ & 3052 & $446,5-7271$ & 0,49 & $-1,97$ & Sc & 0,043 & $0,02-0,11$ & 2,24 & 6,02 \\
\hline B & 972,3 & $715-1470$ & 0,89 & $-0,68$ & $\mathbf{Y}$ & 0,034 & $0,02-0,05$ & 0,68 & $-1,03$ \\
\hline Al & 101,4 & $6,45-390,1$ & 1,86 & 3,46 & $\mathrm{Hg}$ & 0,025 & $0-0,06$ & 1,21 & 1,13 \\
\hline $\mathbf{P}$ & 84,33 & $34,2-304,9$ & 2,94 & 8,98 & $\mathbf{G a}$ & 0,022 & $0-0,05$ & 0,27 & 0,55 \\
\hline $\mathbf{L i}$ & 69,16 & $57,27-86,66$ & 0,57 & $-0,48$ & $\mathbf{Z r}$ & 0,018 & $0,01-0,05$ & 2,27 & 5,94 \\
\hline $\mathbf{B a}$ & 56,50 & $40,5-80$ & 0,60 & $-1,39$ & Cd & 0,017 & $0,01-0,05$ & 2,37 & 6,63 \\
\hline $\mathbf{R b}$ & 40,54 & $37,28-44,74$ & 0,08 & $-1,49$ & Eu & 0,015 & $0,01-0,03$ & 1,57 & 2,84 \\
\hline Zn & 26,30 & $11,35-51,23$ & 0,97 & 0,79 & In & 0,013 & $0-0,09$ & 3,03 & 9,34 \\
\hline As & 9,724 & $6,96-15,28$ & 1,09 & 0,48 & $\mathrm{Ce}$ & 0,011 & $0-0,02$ & 0,86 & $-0,38$ \\
\hline Mn & 8,405 & $2,45-22,58$ & 1,36 & 2,02 & Th & 0,010 & $0-0,03$ & 2,40 & 6,47 \\
\hline Fe & 5,949 & $0,98-18,05$ & 1,80 & 3,52 & Gd & 0,009 & $0-0,03$ & 2,74 & 8,09 \\
\hline Mo & 4,287 & $2,33-12,01$ & 2,18 & 4,70 & Hf & 0,009 & $0-0,02$ & 1,86 & 3,26 \\
\hline $\mathrm{Cu}$ & 2,217 & $0,24-8,37$ & 2,29 & 6,16 & La & 0,008 & $0-0,02$ & 1,48 & 1,57 \\
\hline $\mathbf{N i}$ & 1,957 & $1,63-3,42$ & 2,91 & 8,86 & Tl & 0,008 & $0-0,04$ & 2,36 & 5,94 \\
\hline $\mathbf{U}$ & 1,725 & $1,34-2,01$ & $-0,15$ & $-0,32$ & Nd & 0,007 & $0-0,03$ & 2,50 & 6,79 \\
\hline $\mathbf{V}$ & 1,258 & $0,93-1,97$ & 1,79 & 4,30 & Sm & 0,006 & $0-0,02$ & 3,11 & 9,76 \\
\hline $\mathrm{Sb}$ & 0,780 & $0,45-1,39$ & 1,42 & 2,68 & Yb & 0,005 & $0-0,02$ & 3,08 & 9,59 \\
\hline $\mathbf{W}$ & 0,476 & $0,36-0,86$ & 1,84 & 3,13 & Er & 0,005 & $0-0,02$ & 3,09 & 9,68 \\
\hline Cs & 0,352 & $0,28-0,66$ & 2,87 & 8,61 & Dy & 0,005 & $0-0,02$ & 2,99 & 9,20 \\
\hline Te & 0,294 & $0,15-0,88$ & 2,80 & 8,31 & Bi & 0,004 & $0-0,03$ & 2,93 & 8,90 \\
\hline $\mathbf{T i}$ & 0,235 & $0,09-0,55$ & 1,18 & 0,34 & Pr & 0,003 & $0-0,02$ & 3,08 & 9,62 \\
\hline $\mathrm{Se}$ & 0,232 & $0,12-0,45$ & 1,11 & 0,67 & Lu & 0,003 & $0-0,02$ & 3,14 & 9,87 \\
\hline Sn & 0,228 & $0,02-1,28$ & 2,99 & 9,20 & Ho & 0,003 & $0-0,02$ & 3,13 & 9,85 \\
\hline Co & 0,153 & $0,04-0,57$ & 2,32 & 5,78 & $\mathbf{T b}$ & 0,003 & $0-0,02$ & 3,14 & 9,90 \\
\hline Ta & 0,134 & $0,09-0,24$ & 1,69 & 3,00 & Tm & 0,003 & $0-0,02$ & 3,13 & 9,84 \\
\hline Ag & 0,127 & $0,03-0,64$ & 2,68 & 7,53 & & & & & \\
\hline
\end{tabular}

Çalışmada ayrıca göl suyunda ölçülen ağır metal ve eser element seviyeleri bazı çevresel düzenleme ve yönetmelik değerleri ile kıyaslanmıştır. Göl suyunda ölçülen elementel konsantrasyonların yönetmelik ve düzenlemelerde verilen sınır değerler ile kıyaslandığında yüksek olmadığı belirlenmiştir. Tablo 2'de Su Kirliliği Kontrolü Yönetmeliği, su kaynaklarının sınıflarına göre kalite kriterleri; Yerüstü Su Kalitesi Yönetmeliği, yerüstü su kaynakları için belirli kirleticiler ve çevresel kalite standartları, sulamada kullanılacak sularda kabul edilebilen maksimum konsantrasyonlar ile hayvanların içme suyu kullanımı gerekli kalite kriterleri ve Alabalık ve Sazan Türü Balıkların Yaşadığı Suların Korunması ve İyileştirilmesi Hakkında Yönetmelik kapsamında, alabalık yetiştiriciliği için su kalite kriterleri verilmektedir. Bu yönetmeliklerdeki sınır ve sınıflama değerleri ile göl suyunda ölçülen değerler kıyaslandığında kıta içi su sınıflarına göre Sodyum ve Fosfor parametreler dışında göl suyu, 1. Sınıf sular kapsamına girmektedir. Sodyum konsantrasyonlarının yüksek olması, gölün acı su 
özelliği ve daha önceden deniz ile bağlantısının olması ile açıklanmaktadır. Diğer yandan, yüksek Fosfor seviyesinin göl suyunun organik içeriğinden kaynaklanmakta olduğu söylenebilir. Buna sebep olarak göl çevresindeki hayvansal ve tarımsal faaliyetler ile göle ulaşan nehir suyunun taşıdığı organik maddeler gösterilebilir. Yerüstü Su Kalitesi Yönetmeliği çevresel su kalitesi standartları açısından kıyaslama yapıldığında ise Al, B, Cu, Si ve Zn için ölçülen değerlerin Yıllık Ortalama - Çevresel Kalite Standardı (Yıllık Ort.-ÇKS) değerlerini aştı̆̆ 1 görülmektedir.

Göl çevresindeki alanlarda gerçekleştirilen tarımsal ve hayvancılık faaliyetlerinde ve göl kıyısında bulunan balık yetiştirme çiftliklerinde göl suyunun kullanıldığı bilinmektedir. Bu nedenle gölde ölçülen ortalama konsantrasyonlar hayvansal ve tarımsal amaçlı kullanılan suların taşıması gereken kalite ölçütleriyle de kıyaslanmıştır. Tablo 2'de verilen sulamada kullanılacak sular için kabul edilebilen maksimum konsantrasyonlar uyarınca gölde ölçülen değerler sulama amaçlı kullanım için uygun görülmektedir. Benzer şekilde element sınır değerleri, hayvansal içme suyu parametreleri ve balık yetiştiriciliği kalite standartlarını da sağlamaktadır.

Tablo 2. Yönetmelik ve düzenlemelerde verilen elementel konsantrasyonlar $(\mu \mathrm{g} / \mathrm{L}, * \mathrm{mg} / \mathrm{L})$ için sınır ve sinıflandırma değerleri

\begin{tabular}{|c|c|c|c|c|c|c|c|c|c|c|c|c|}
\hline \multirow{2}{*}{ 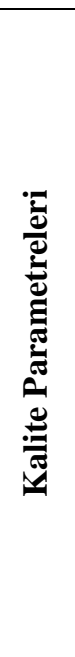 } & \multicolumn{4}{|c|}{$\begin{array}{c}\text { Kıta içi Su Kaynaklarının } \\
\text { Sınflarına göre Kalite } \\
\text { Kriterleri }(\mu \mathrm{g} / \mathrm{L}) \\
{[18]}\end{array}$} & \multicolumn{2}{|c|}{$\begin{array}{c}\text { Yerüstü Su } \\
\text { Kaynakları } \\
\text { için Belirli } \\
\text { Kirleticiler ve } \\
\text { Çevresel } \\
\text { Kalite } \\
\text { Standartları } \\
{[13]}\end{array}$} & \multicolumn{2}{|c|}{$\begin{array}{c}\text { Sulamada } \\
\text { Kullanilacak } \\
\text { Sularda Kabul } \\
\text { Edilebilen } \\
\text { Maksimum } \\
\text { Konsantrasyonlar } \\
\text { [19] }\end{array}$} & \multicolumn{2}{|c|}{$\begin{array}{c}\text { Hayvanların } \\
\text { İcme Suyu } \\
\text { Kullanımı } \\
\text { Gerekli Kalite } \\
\text { Kriterleri } \\
{[19,20]}\end{array}$} & \multirow{2}{*}{$\begin{array}{c}\text { Alabalık } \\
\text { Yetiştirici } \\
\text { liği İçin } \\
\text { Su Kalite } \\
\text { Kriterleri } \\
\text { [21] }\end{array}$} & \multirow[b]{2}{*}{ 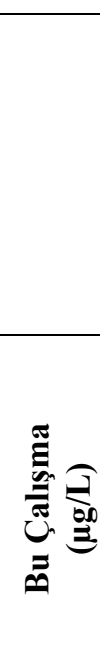 } \\
\hline & $\begin{array}{c}\text { I } \\
\text { Sinıf }\end{array}$ & $\begin{array}{c}\text { II } \\
\text { Sinıf }\end{array}$ & $\begin{array}{c}\text { III } \\
\text { Sinıf }\end{array}$ & $\begin{array}{c}\text { IV } \\
\text { Sinıf }\end{array}$ & 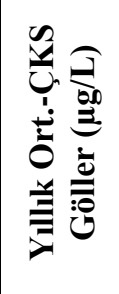 & 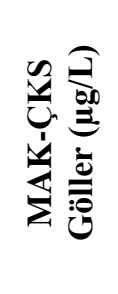 & 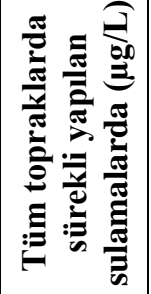 & 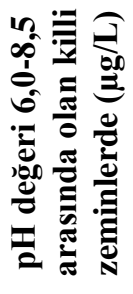 & 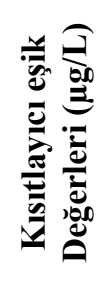 & 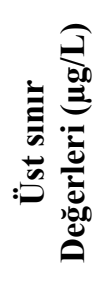 & & \\
\hline Ag & & & & & 1,5 & 1,5 & & & 50 & 50 & & 0,13 \\
\hline Al & 300 & 300 & 1000 & $>1000$ & 2,2 & 27 & 5000 & 20000 & 5000 & 10000 & 100 & 101,4 \\
\hline As & 20 & 50 & 100 & $>100$ & 53 & 53 & 100 & 2000 & 200 & 200 & & 9,7 \\
\hline \multirow{4}{*}{ B } & \multirow{4}{*}{1000} & \multirow{4}{*}{1000} & \multirow{4}{*}{1000} & \multirow{4}{*}{$>1000$} & \multirow{4}{*}{707} & \multirow{4}{*}{1472} & $\begin{array}{l}\text { Hassas } \\
\text { Bitkiler }\end{array}$ & $\begin{array}{l}\text { Hassas } \\
\text { Bitkiler }\end{array}$ & \multirow{4}{*}{5000} & \multirow{4}{*}{30000} & & \multirow{4}{*}{972,3} \\
\hline & & & & & & & 1000 & 2000 & & & & \\
\hline & & & & & & & $\begin{array}{c}\text { Diğer } \\
\text { Bitkiler }\end{array}$ & $\begin{array}{c}\text { Diğer } \\
\text { Bitkiler }\end{array}$ & & & & \\
\hline & & & & & & & 4000 & 6000 & & & & \\
\hline $\mathbf{B a}$ & 1000 & 2000 & 2000 & $>2000$ & 680 & 680 & & & 1000 & 1000 & 5000 & 56,5 \\
\hline $\mathbf{B e}$ & & & & & 2,5 & 3,9 & 100 & 500 & 100 & 100 & & 0,1 \\
\hline $\mathbf{C a}^{*}$ & & & & & & & & & 100 & 200 & $4-160$ & 58,7 \\
\hline \multirow{4}{*}{ Cd } & \multirow{4}{*}{3} & \multirow{4}{*}{5} & \multirow{4}{*}{10} & \multirow{4}{*}{$>10$} & $\begin{array}{c}0,08 \\
(\text { Snf } 1) \\
0,08 \\
(\text { Snf 2) } \\
\end{array}$ & $\begin{array}{c}0,45 \\
(\text { Snf } 1) \\
0,45 \\
(\text { Snf } 2) \\
\end{array}$ & \multirow{4}{*}{10} & \multirow{4}{*}{50} & \multirow{4}{*}{10} & \multirow{4}{*}{50} & \multirow{4}{*}{3} & \multirow{4}{*}{0,02} \\
\hline & & & & & $\begin{array}{c}0,09 \\
(\text { Snf 3) } \\
\end{array}$ & $\begin{array}{c}0,6 \\
(\operatorname{Snf} 3) \\
\end{array}$ & & & & & & \\
\hline & & & & & $\begin{array}{c}0,15 \\
(\operatorname{Snf} 4)\end{array}$ & $\begin{array}{c}0,9 \\
(\operatorname{Snf} 4)\end{array}$ & & & & & & \\
\hline & & & & & $\begin{array}{c}0,25 \\
(\text { Snf 5) }\end{array}$ & $\begin{array}{c}1,5 \\
(\text { Snf 5) }\end{array}$ & & & & & & \\
\hline Co & 10 & 20 & 200 & $>200$ & 0,3 & 2,6 & 50 & 5000 & 1000 & 1000 & & 0,2 \\
\hline
\end{tabular}




\begin{tabular}{|c|c|c|c|c|c|c|c|c|c|c|c|c|}
\hline \multirow{2}{*}{ 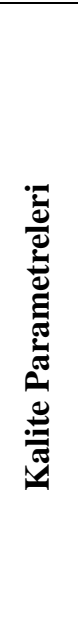 } & \multicolumn{4}{|c|}{$\begin{array}{c}\text { Kıta içi Su Kaynaklarının } \\
\text { Sinıflarına göre Kalite } \\
\text { Kriterleri }(\mu \mathrm{g} / \mathrm{L}) \\
{[18]}\end{array}$} & \multicolumn{2}{|c|}{$\begin{array}{c}\text { Yerüstü Su } \\
\text { Kaynakları } \\
\text { için Belirli } \\
\text { Kirleticiler ve } \\
\text { Çevresel } \\
\text { Kalite } \\
\text { Standartları } \\
{[13]}\end{array}$} & \multicolumn{2}{|c|}{$\begin{array}{c}\text { Sulamada } \\
\text { Kullanılacak } \\
\text { Sularda Kabul } \\
\text { Edilebilen } \\
\text { Maksimum } \\
\text { Konsantrasyonlar } \\
{[19]}\end{array}$} & \multicolumn{2}{|c|}{$\begin{array}{c}\text { Hayvanların } \\
\text { İçme Suyu } \\
\text { Kullanımı } \\
\text { Gerekli Kalite } \\
\text { Kriterleri } \\
{[19,20]}\end{array}$} & \multirow{2}{*}{ 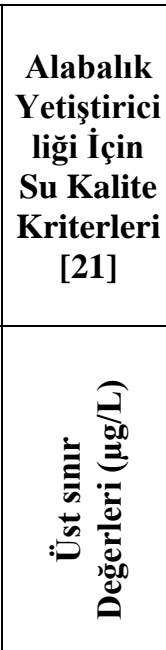 } & \multirow[b]{2}{*}{ 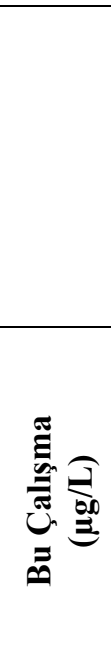 } \\
\hline & $\underset{\text { Sinıf }}{\text { I }}$ & $\underset{\text { Sinif }}{\text { II }}$ & $\begin{array}{c}\text { III } \\
\text { Sinıf }\end{array}$ & $\begin{array}{c}\text { IV } \\
\text { Sinıf }\end{array}$ & 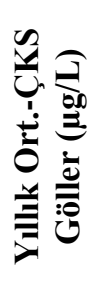 & 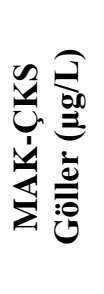 & 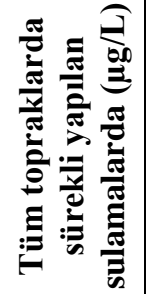 & 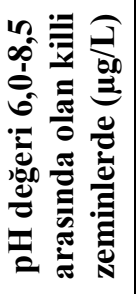 & 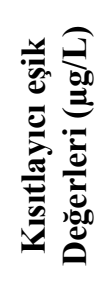 & 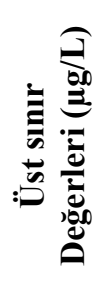 & & \\
\hline $\mathrm{Cr}$ & 20 & 50 & 200 & $>200$ & 1,6 & 142 & 100 & 1000 & 100 & 1000 & 50 & 0,1 \\
\hline $\mathrm{Cu}$ & 20 & 50 & 200 & $>200$ & 1,6 & 3,1 & 200 & 5000 & 200 & 500 & 10 & 2,2 \\
\hline $\mathbf{F e}$ & 300 & 1000 & 5000 & $>5000$ & 36 & 101 & 5000 & 20000 & 200 & 400 & 500 & 5,9 \\
\hline $\mathrm{Hg}$ & 0,1 & 0,5 & 2 & $>2$ & - & 0,07 & & & 10 & 10 & 0,05 & 0,025 \\
\hline $\mathbf{K}^{*}$ & & & & & & & & & 20 & 20 & & 118,3 \\
\hline $\mathbf{L i}$ & & & & & & & 2500 & - & & & & 69,2 \\
\hline Mg & & & & & & & & & 50 & 100 & & 385860 \\
\hline Mn & 100 & 500 & 3000 & $>3000$ & & & 200 & 10000 & 50 & 500 & 10 & 8,4 \\
\hline Mo & & & & & & & 10 & 50 & 30 & 60 & & 4,3 \\
\hline $\mathrm{Na}^{*}$ & 125 & 125 & 250 & $>250$ & & & & & 50 & 300 & & 3152 \\
\hline $\mathrm{Ni}$ & 20 & 50 & 200 & $>200$ & 4 & 34 & 200 & 2000 & 250 & 1000 & 50 & 2 \\
\hline $\mathbf{P}$ & 20 & 160 & 650 & $>650$ & & & & & 700 & 700 & $100-3000$ & 84,3 \\
\hline $\mathbf{P b}$ & 10 & 20 & 50 & $>50$ & 1,2 & 14 & 3000 & 5000 & 50 & 100 & 1 & 0,1 \\
\hline $\mathbf{S b}$ & & & & & 7,8 & 103 & & & & & & 0,8 \\
\hline Se & 10 & 15 & 20 & $>20$ & & & 20 & 50 & 50 & 100 & & 0,2 \\
\hline $\mathbf{S i}$ & & & & & 1830 & 1830 & & & & & & 3052 \\
\hline Sn & & & & & 13 & 13 & & & & & & 0,2 \\
\hline $\mathbf{T i}$ & & & & & 26 & 42 & & & & & & 0,2 \\
\hline $\mathbf{V}$ & & & & & 1,6 & 97 & 100 & 1000 & 100 & 100 & & 1,3 \\
\hline $\mathbf{Z n}$ & 200 & 500 & 2000 & $>2000$ & 5,9 & 231 & 2000 & 5000 & 5000 & 25000 & 100 & 26,3 \\
\hline
\end{tabular}

Bafa Gölü’nde 2012 yılında Yılgör [8] tarafından yapılan çalışmada pH değerleri 8,10 ile 8,30 arasında, elektriksel iletkenlik ise ortalama $23200 \mu \mathrm{s} / \mathrm{cm}$ olarak ölçülürken bu çalışmada da benzer sonuçlar bulunmuştur. Diğer taraftan Yabanlı ve diğerlerinin [17] çalışmasında, göl suyunda ölçülen $\mathrm{Cd}, \mathrm{Cr}, \mathrm{Hg}$, ve $\mathrm{Pb}$ değerleri bu çalışmada bulunan değerlerden yüksek olmakla beraber, $\mathrm{Al}, \mathrm{As}, \mathrm{Cu}$ ve $\mathrm{Ni}$ değerleri ise daha düşüktür. $\mathrm{Hg}$ ve $\mathrm{Pb}$ haricinde diğer element değerleri nispeten yakın konsantrasyonlardadır. Bu durum göl suyunun y1llara bağlı olarak çok fazla değişim göstermediğini ortaya koymaktadir.

Tablo 3'te ülkemiz göllerinde ölçülen bazı element konsantrasyonları verilmektedir. Bafa Gölü su kalitesi ülkemizdeki diğer göl suları ile kıyaslandığında ise antropojenik kökenli element değerleri açısından daha düşük değerlere sahip olduğu ortaya çıkmaktadır. Diğer taraftan doğal kökenli element (Al, As, Si gibi) konsantrasyonları ise daha yükssek ölçülmüştür. 
Tablo 3. Ülkemiz göllerinde ölçülen bazı element konsantrasyonları, $\mu \mathrm{g} / \mathrm{L}$

\begin{tabular}{|l|c|c|c|c|c|c|c|c|c|c|}
\hline Element & $\begin{array}{c}\text { Bafa } \\
\text { Gölü } \\
\text { (Bu } \\
\text { Calı̧ma) }\end{array}$ & $\begin{array}{c}\text { Bafa } \\
\text { Gölü } \\
{[17]}\end{array}$ & $\begin{array}{c}\text { Beyşehir } \\
\text { Gölü } \\
{[22]}\end{array}$ & $\begin{array}{c}\text { Ĕgirdir } \\
\text { Gölü } \\
{[3]}\end{array}$ & $\begin{array}{c}\text { Kovada } \\
\text { Gölü } \\
{[6]}\end{array}$ & $\begin{array}{c}\text { Sapanca } \\
\text { Gölü } \\
{[23]}\end{array}$ & $\begin{array}{c}\text { Abant } \\
\text { Gölü } \\
{[23]}\end{array}$ & $\begin{array}{c}\text { Van } \\
\text { Gölü } \\
{[24]}\end{array}$ & $\begin{array}{c}\text { Mogan } \\
\text { Gölü } \\
{[25]}\end{array}$ & $\begin{array}{c}\text { Keban } \\
\text { Baraj } \\
\text { Gölü } \\
{[2]}\end{array}$ \\
\hline Al & 101,4 & 14,2 & 97,0 & & 38,0 & & & & 0,9 & \\
\hline As & 9,72 & 4,7 & 2,4 & & & & & & & \\
\hline $\mathbf{C d}$ & 0,02 & 0,1 & & 2,3 & & 3,0 & 2,5 & 4,4 & & \\
\hline $\mathbf{C r}$ & 0,12 & 2,6 & 2,7 & 0,1 & & 62,0 & 64,3 & 4,1 & & \\
\hline $\mathbf{C u}$ & 2,22 & 0,4 & 1,6 & 0,5 & & 18,2 & 24,6 & & & \\
\hline $\mathbf{F e}$ & 5,95 & & 273,0 & 1,4 & 477,5 & & & 829,3 & 1,5 & \\
\hline $\mathbf{H g}$ & 0,03 & 13,0 & & & & & & & & \\
\hline $\mathbf{M n}$ & 8,40 & & 34,5 & 111,1 & 63,3 & 22,6 & 34,9 & 137,7 & & \\
\hline $\mathbf{M o}$ & 4,29 & & & 51,7 & & & & & & \\
\hline $\mathbf{N i}$ & 1,96 & 0,6 & 2,9 & 1,1 & 10,0 & 46,4 & 51,4 & & & 4,51 \\
\hline $\mathbf{P b}$ & 0,07 & 1,2 & 0,8 & & & 35,7 & 36,9 & 39,9 & & 0,32 \\
\hline $\mathbf{S e}$ & 0,23 & & & 3,4 & & & & & & \\
\hline $\mathbf{S i}$ & 3051,5 & & & & & & & & 203,6 & \\
\hline $\mathbf{Z n}$ & 26,30 & & & 17,2 & 19,5 & 88,5 & 21,8 & 37,0 & & \\
\hline
\end{tabular}

\section{Sonuç ve Öneriler}

Bafa Gölü'nde elementel açıdan su kalitesinin belirlenmesi amacıyla yapılan çalışmada 61 elementin konsantrasyonları ölçülmüştür. Elde edilen bulgular 1şığında element konsantrasyonları farklı kaynaklarda ve yönetmeliklerde verilen sınır ve sınıflandırma değerleri ile kıyaslandığında elementel açıdan göl suyu kirlilik seviyesinin yüksek olmadığı ortaya çıkmıştır. Su Kirliliği Kontrolü Yönetmeliği'nde verilen kıta içi su kaynaklarının sınıflandırılmasına göre gölün su kalitesi P, Na ve B parametreleri haricinde 1. Sınıf sular kapsamına dâhil olmaktadır. Bununla birlikte toksik etkiler gösterebilen ve antropojenik kökenli olabilen $\mathrm{As}, \mathrm{Cd}, \mathrm{Cr}, \mathrm{Hg}, \mathrm{Pb}, \mathrm{V}$, Co ve $\mathrm{Ni}$ elementlerinin konsatrasyonları Yerüstü Su Kalitesi Yönetmeliği'nde verilen yıllık ortalama ve maksimum çevresel kalite standartlarını sağlamaktadır. Bunların dışında sadece $\mathrm{Al}, \mathrm{B}, \mathrm{Cu}, \mathrm{Si}$ ve $\mathrm{Zn}$ değerleri bazı örnekleme noktalarında yıllık ortalama çevresel kalite standartlarının bir miktar üzerinde ölçülmüştür. Ayrıca sulamada kullanılacak sular için kabul edilebilen maksimum konsantrasyonlar ve hayvansal içme suyu için belirlenen maksimum konsantrasyonlar dikkate alındığında gölde ölçülen element konsantrasyonları bu amaçlara uygun görülmüştür.

Göl suyunda ölçülen fosfor konsantrasyonlarının yüksek olması, göl suyunun organik kirliliğinin yüksek olabileceği sonucunu ortaya koymaktadır. Bu çalışmada bu durumu destekleyecek olan organik kirliliğin göstergesi olan çözünmüş oksijen, redoks potansiyeli, kimyasal oksijen ihtiyacı vb. gibi parametreler ölçülmemiş olsa da daha önce yapılmış çalışmalar bu durumu desteklemektedir. Göl civarında hızlı bir şekilde artış gösteren balık çiftliklerinin çevresel etkilerini azaltacak önlemlerin alınması, tarımsal faaliyetlerde gereksiz ve aşırı gübre kullanımının önlenmesi ve gölün yanından geçen yol üzerine kurulan küçük çaplı işletmelerin atık sularının bertaraf edilmesi göldeki organik kirliliği azaltacaktır.

Bafa Gölü su kalitesinin izlenmesine yönelik olarak yapılacak olan devam çalışmalarında organik kirliliğin belirlenmesine yönelik olarak çözünmüş oksijen, redoks potansiyeli, kimyasal oksijen ihtiyacı vb. gibi parametrelerin ölçülmesi uygun olacaktır. Buna ilaveten son yıllarda önemi gittikçe artan ve gölde daha önce hiç çalışılmamış olan endokrin bozucu kimyasalların (Pestisit türleri ve Poliklorlu bifeniller (PCB'ler)) ölçülmesi göl suyu kalitesi hakkında daha fazla bilgi sağlayacaktır. 


\section{Kaynaklar}

[1] Singare P.U., Talpade M.S., Dagli D.V., Bhawe V.G. 2013. Heavy Metal Content in Water of Bhavan's College Lake of Andheri, Mumbai, International Letters of Chemistry, Physics and Astronomy, 13: 94-104.

[2] Topal M., Arslan-Topal E.I. 2017. Su Çerçeve Direktifi Kapsamında Keban Baraj Gölü'nde (Elazığ) Kurşun ve Nikel Konsantrasyonlarının Belirlenmesi, International Journal of Pure and Applied Sciences, 3 (1): 41-53.

[3] Kaptan H., Tekin-Özan S. 2014. Eğirdir Gölü’nün (Isparta) Suyunda, Sedimentinde ve Gölde Yaşayan Sazan'ın (Cyprinus carpio L., 1758) Bazı Doku ve Organlarındaki Ağır Metal Düzeylerinin Belirlenmesi, SDU Journal of Science (E-Journal), 9 (2): 44-60.

[4] Zinabu G.M., Pearce N.J.G. 2003. Concentrations of heavy metals and related trace elements in some Ethiopian rift-valley lakes and their in-flows, Hydrobiologia, 492 (1): 171-178.

[5] Ogoyi D., Mwita C.J., Nguu E.K., Shiundu P.M. 2011. Determination of Heavy Metal Content in Water, Sediment and Microalgae from Lake Victoria, East Africa, The Open Environmental Engineering Journal, 4: 156-161.

[6] Kır İ., Tekin-Özan S., Tuncay Y. 2007. Kovada Gölü’nün Su ve Sedimentindeki Bazı Ağır Metallerin Mevsimsel Değişimi, E.U. Journal of Fisheries \& Aquatic Sciences, 24 (1-2): 155-158.

[7] Kırmızıgül O. 2013. Gökçekaya Baraj Gölü Dip Sedimentinin Ağır Metal Düzeylerinin Belirlenmesi. Gazi Üniversitesi, Çevre Bilimleri Anabilim Dalı, Yüksek Lisans Tezi, 71s, Ankara.

[8] Yılgör S. 2012. Bafa Gölü Sedimanlarındaki Ağır Metal Kirliliğinin Araştırılması. Dokuz Eylül Üniversitesi, Deniz Bilimleri ve Teknolojisi Bölümü, Deniz Jeolojisi ve Jeofiziği Programı, Doktora Tezi, 64s, İzmir.

[9] Jin Z.D., You C.F., Yu T.L., Wang B.S. 2010. Sources and flux of trace elements in river water collected from the Lake Qinghai catchment, NE Tibetan Plateau, Applied Geochemistry, 25 (10): 1536-1546.

[10] Metin-Dereli E., Ertürk A., Çakmakçı M. 2017. Yüzeysel Sularda Ağır Metallerin Etkileri Ve Ötrofikasyon ile İlişkisi, Turkish Journal Of Aquatic Sciences, 32 (4): 214-230.

[11] Rigaud S., Radakovitch O., Couture R-M., Deflandre B., Cossa D., Garnier C., Garnie J-M. 2013. Mobility and fluxes of trace elements and nutrients at the sediment-water interface of a lagoon under contrasting water column oxygenation conditions. Applied Geochemistry, 31: 35-51

[12] Gashi F., Frančišković-Bilinski S., Bilinski H., Haziri A., Gashi S. 2016. Assessing the trace element content in water samples from Badovci Lake (Kosovo) using inductively coupled plasmamass spectrometry analysis, Arabian Journal of Geosciences, 9 (6): 454.

[13] YSKY 2012. Yerüstü Su Kalitesi Yönetmeliği. Resmi Gazete No 28483, Orman ve Su İşleri Bakanlığı, Ankara.

[14] ÇOB 2007. Türkiye'de Su Sektörü için Kapasite Geliştirme Projesi, Çevre ve Orman Bakanlığı, Ankara.

[15] Çokay E., Eker S., Ersöz D., Karapınar İ., Karaman Ş. 2017. Evaluation of Metal Pollution in Büyük Menderes River Under the EU Water Framework Directive, $2^{\text {nd }}$ International Conference On Civil And Environmental Engineering, Nevşehir, 8 - 10 Mayıs, 2537-2549.

[16] TÜBİTAK 2010. Havza Koruma Eylem Planlarının Hazırlanması Projesi Büyük Menderes Havzası, Türkiye Bilimsel ve Teknolojik Araştırma Kurumu Marmara Araştırma Merkezi Çevre Enstitüsü (TÜBITTAK MAM), Gebze, Kocaeli.

[17] Yabanlı M., Coşkun Y., Öz B., Yozukmaz A., Sel F., Öndeş S. 2013. Bafa Gölü’nden Elde Edilen Levreklerde (Dicentrarchus labrax) ve Göl Suyunda Ağır Metal İçeriğinin Belirlenmesi ve Balık/Halk Sağlığı Açısından Durum Değerlendirmesi, Bornova Veteriner Bilimleri Dergisi, 35 (49): 15-23.

[18] SKKY 2004. Su Kirliliği Kontrolü Yönetmeliği. Resmi Gazete No 25687, Çevre ve Orman Bakanlığı, Ankara.

[19] SSKKSYKHY 2015. Sulama Sularının Kalitesi Ve Kullanılmış Suların Yeniden Kullanılması Hakkında Yönetmelik Taslağı. Orman ve Su İşleri Bakanlığı, Su Yönetimi Genel Müdürlüğü, Ankara. 
[20] Socha M.T., Ensley S.M., Tomlinson D.J., Johnson A.B. 2003. Variability of water composition and potential impact on animal performance, Intermountain Nutrition Conference, pp85-96, Salt Lake C, UT., Utah State Universty, Logan.

[21] ASTBYSKİHY, 2014. Alabalık Ve Sazan Türü Balıkların Yaşadığı Suların Korunması ve İyileştirilmesi Hakkında Yönetmelik. Resmi Gazete No 28880, Gıda, Tarım ve Hayvancılık Bakanlığı, Ankara.

[22] Üçüncü-Tunca E. 2016. Beyşehir Gölü’nde Su ve Sedimentte Ağır Metal Birikimi ve Sedimentte Antropojenik Kontaminasyon Değerlendirmesi, Ordu Üniversitesi Bilim Ve Teknoloji Dergisi, 6 (2): 205-219.

[23] Duman F. 2005. Sapanca ve Abant Gölü Su, Sediment ve Sucul Bitki Örneklerinde Ağır Metal Konsantrasyonlarının Karşılaş̧ırmalı Olarak İncelenmesi. Ankara Üniversitesi, Biyoloji Anabilim Dal1, Doktora Tezi, 227s, Ankara.

[24] Zengin O. 2008. Van Gölü Ve Gölü Besleyen Kaynaklarda Ağır Metal Kirliliğinin Araştırılması. Yüksek Lisans Tezi, Gazi Üniversitesi Fen Bilimleri Enstitüsü, Ankara.

[25] Benzer S., Arslan H., Uzel N., Gül A., Y1lmaz M. 2013. Concentrations of metals in water, sediment and tissues of Cyprinus carpio L., 1758 from Mogan Lake (Turkey), Iranian Journal of Fisheries Sciences, 12 (1): 44-55. 